\title{
Effects of EHR Use on Patient Participation
}

\author{
William Ventres, MD, MA \\ Department of Family and Preventive Medicine, University of Arkansas for Medical Sciences, Little Rock, AR, USA.
}

I enjoyed reading the article by Street and colleagues on how physicians' use of Electronic Health Records (EHRs) affects patient participation. ${ }^{1}$ Sadly, little seems to have changed since over a decade ago, when I explored roughly the same subject (admittedly using far less sophisticated quantitative measures and a much smaller sample). ${ }^{2}$ The triadic interplay between physicians, patients, and EHRs has always been difficult to navigate, influenced as it is by many technical, relational, and organizational issues. ${ }^{3}$

This question remains: On what should we focus our attention, the patient or the EHR?

Some clinicians suggest that EHRs, by providing expansive access to patient information, best pave the way for patientcentered care. Others - I among them - contend that patientcentered care can only occur by pushing examination room computers to the side, at least momentarily, while interacting with patients.

For those who hold similar sentiments, that we should use our face-to-face time with patients as therapeutic crucibles for encouraging health in addition to diagnosing and treating disease, ${ }^{4}$ I make the following recommendations:

1. Look at your patients-Make them the focus of your consultations, and resist the distracting pull of technology made manifest by the computer screen. ${ }^{5}$

2. Open your ears - Let patients' stories, full of diagnostic cues and therapeutic context, emerge in their telling.

3. Organize in "real time"-Prepare mental notes before retrieving data or entering text in the computer.

4. Write "get to the point" notes-Hit the highlights, distilling key information and clinical reasoning, and find ways to marginalize the superfluous data that make EHR notes challenging to wade through.

5. Remember patients as people (rather than as a collection of digitalized data points)-This will help create rich mental images of your patients that no record keeping system, electronic or otherwise, can accurately begin to approximate.

As to the future, scribes may provide a reasonable solution (albeit one that will likely not trickle down to safety net clinics serving those most in need), and perhaps technology will catch up to the needs of human beings on both sides of the stethoscope. And just possibly I am wrong, and the holy grail of doctor-patient encounters truly exists in the space between pixels.

Only I would not bet on it. Best, now, is to find ways of thoughtfully managing the space between us and our patients, making it as engaging as possible given the many constraints to therapeutic relationship-building that currently exist.

Corresponding Author: William Ventres, MD, MA; Department of Family and Preventive Medicine, University of Arkansas for Medical Sciences, Little Rock, AR, USA (e-mail: wventres@uams.edu).

\section{Compliance with Ethical Standards:}

Conflict of Interest: The author declares that he does not have a conflict of interest.

\section{REFERENCES}

1. Street RL, Liu L, Farber NJ, et al. Keystrokes, mouse clicks, and gazing at the computer: how physician interaction with the EHR affects patient participation. J Gen Intern Med 33(4):423-8.

2. Ventres W, Kooienga S, Marlin R, Vuckovic N, Stewart V. Clinician style and examination room computers: a video ethnography. Fam Med 2005;37(4):276-81.

3. Ventres W. Kooeniga S, Marlin R, Vuckovic $\mathbf{N}$, Nygren $\mathbf{P}$, Stewart $\mathbf{V}$. Physicians, patients, and the electronic health record: an ethnographic analysis. Ann Fam Med 2006;4:124-31.

4. Ventres WB. Healing. Ann Fam Med 2016;14(1):76-8.

5. Loxterkamp D. Distraction, disengagement, and the purpose of medicine. In: Papadakos PJ, Bertman S, eds. Distracted Doctoring: Returning to Patient-Centered Care in the Digital Age. New York: Springer International Publishing AG 2017;61-70. 